\title{
Intra-annual Runoff Distribution in the Pripyat River Basin
}

\author{
Alexander Volchak $^{1}$, Sergey Parfomuk ${ }^{1, *}$ and Svetlana Sidak ${ }^{1}$ \\ ${ }^{1}$ Brest State Technical University, 224017 Brest, Republic of Belarus
}

\begin{abstract}
The time variability features of the intra-annual runoff distribution in the Pripyat River basin at the present stage are considered. The study used data from 10 active gauging-stations at the basin area for the period of enabled observations. Changes in the nature of natural runoff regulation of rivers are shown. An increase in the coefficient of natural runoff regulation after the period 1970-1983 for the rivers of the Pripyat River basin was revealed. The relationship between the coefficient of uneven runoff and the share of spring flood was established.

Keywords: intra-annual runoff distribution, daily runoff duration curve, coefficient of natural runoff regulation, spring flood share.
\end{abstract}

\section{Introduction}

The periods of cooling and warming, dry and wet periods alternate in time and the general state of water resources and their quality do not statistically change. So, studying of water resources and impact of climate change and anthropogenic activities on runoff is an urgent worldwide task [1-5].

The task of analysis and subsequent modelling of water resources is one of the most important for the state [6]. Water resources analysis was conducted in terms of studying the water regime of rivers, lakes and reservoirs. The Soil and Water Assessment Tool (SWAT) is using for simulate water, sediment, and nutrient yield in a watershed by using input data from GIS and applying different agricultural practices, climate change, and land [7-9]. The Soil and Water Integrated Model (SWIM) has been used to study various hydrological phenomena, such as runoff change causing by climate influence, extreme flood analysis, agricultural production, etc. [10-13]. Using artificial intelligence methods as an approach in solving complex nonlinear problems and lake level forecasting has been increased [14-17]. Previously, we performed the assessment of water resources of the Republic of Belarus in the beginning of 20th century [18]. Modelling of the water regime in Belarus was carried out on the basis of mathematical models [19].

The study of intra-annual runoff distribution (IARD) of rivers is an important scientific and practical aspect of organizing cost-effective and environmentally safe water use [20-23].

\footnotetext{
* Corresponding author: parfom@mail.ru
} 
Water resources use is based on the IARD parameters and planned for various water management purposes, as well as for determining the main parameters of reservoirs and hydraulic structures.

Establishing patterns of runoff distribution in a year is a difficult task since the IARD is affected by a number of interrelated factors, the quantitative accounting of which is almost impossible to fully account for. First of all, the distribution of runoff depends on changes in the intra-annual course of air temperature and precipitation distribution. In addition to climatic factors, the runoff distribution is influenced by other physical and geographical parameters that express the natural runoff regulation in the basin. This group of factors includes the size and topography of the basin, hydrogeological conditions, lakes, forest cover, waterlogging, etc. [24].

In General, water users and consumers are interested in a constant stable runoff without interruptions and sharp rises. This means that the river runoff with a high degree of natural regulation is most favourable for them. A low degree of natural regulation is a danger in the form of floods that lead to economic damage and even loss of life.

This problem is particularly relevant for the Belarusian Polesie which main river is the Pripyat River and it is characterized by frequent flooding [25]. As a result of changes in factors and conditions for the formation of runoff within the Pripyat River basin due to hydraulic reclamation, as well as the impact of modern climate changes the water regime of rivers has been significantly transformed. Therefore, an urgent task is to assess changes in the intra-annual distribution of river runoff in modern conditions, which must be taken into account when solving a number of scientific and practical problems.

The purpose of the research is to analyse the current features of the time variability of the intra-annual runoff distribution in the Pripyat River basin and take into account the intra-annual unevenness of the runoff to assess the hydro-ecological safety of the territory.

\section{Data and methods}

The initial data were the observation materials of the Ministry of natural resources and environmental protection of the Republic of Belarus for the period of instrumental observations, published in the materials of the state cadastres. The study used data on average monthly runoff for 10 gauging-stations with the longest observation period (at least 65 years) located in different parts of the Pripyat River basin and differing in morphometric parameters. In addition, data on daily runoff was also used for a number of rivers. Statistical data processing and calculation were performed using the MS Excel package.

\section{Results and discussion}

An analysis of the non-calendar runoff distribution and generally accepted chronological runoff distribution graphs were used to determine the unevenness of the intra-annual runoff distribution (Fig. 1). This feature was implemented in the form of the daily runoff duration curve which is a curve that can be used to set the length of time (in days or as a percentage of the year) during which the runoff is equal to or exceeds the specified [26].

Fig. 2 shows the daily runoff duration curve of the Tsna River which is a tributary of the Pripyat River. The curve based on typical runoff does not match the actual data. Therefore, this method can lead to significant errors when calculating the parameters of the intraannual runoff distribution. 


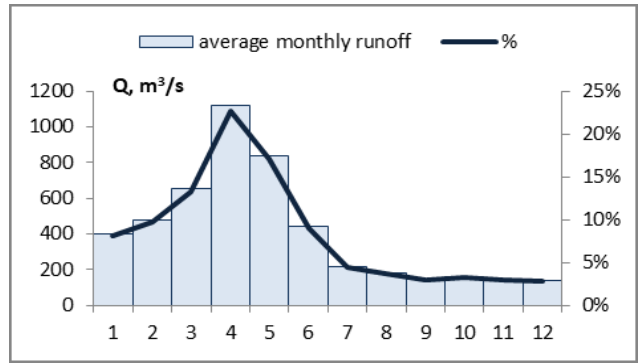

a

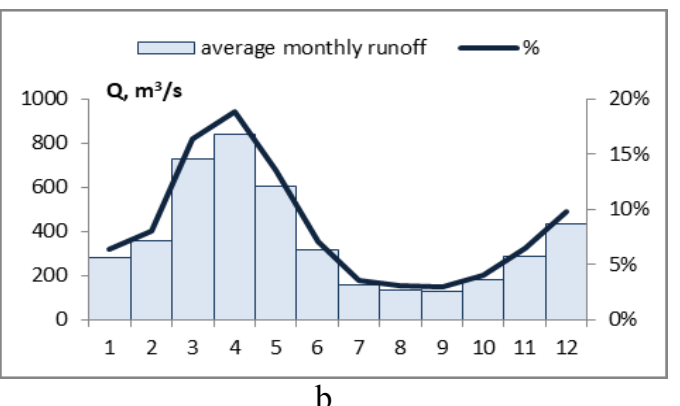

b

Fig. 1. The intra-annual runoff distribution of the Pripyat River at the Mozyr station (a - 1983, b - 2017)

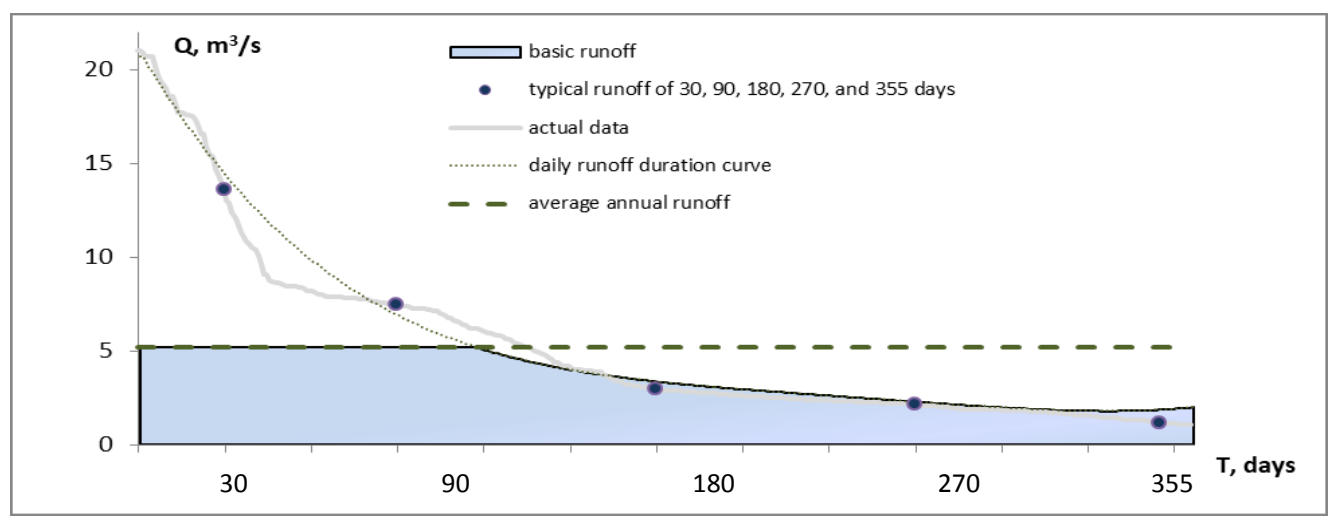

Fig. 2. The daily runoff duration curve of the Tsna River at the Dyatlovichi station, 2004

The coefficient of natural runoff regulation ( $\varphi$-coefficient) which is equal to the ratio of the basic runoff $Q_{b}$ to the total annual runoff is used to study the unevenness of the IARD [27]:

$$
\varphi=\frac{\sum_{i=1}^{n} Q_{b_{i}}}{n \cdot Q_{0}}
$$

where $Q_{b_{i}}=\left\{\begin{array}{l}Q_{0}, \text { if } Q_{i} \geq Q_{0} \\ Q_{i}, \text { if } Q_{i}<Q_{0}\end{array}, Q_{0}\right.$ - average annual runoff, $n$ - number of days per year.

The data of daily and monthly runoff of the rivers in the Pripyat River basin were used to calculate the coefficient of natural runoff regulation. The monthly values of the $\varphi$ coefficient were compared with the coefficients for the daily runoff of the 10 rivers in the Pripyat River basin for the period 1971-2004 to assess the representativeness of calculated results (Fig. 3). The values of the $\varphi$-coefficient that were obtained in two ways were very close to each other. The correlation coefficient was $0.98-0.99$. If you take the values of the $\varphi$-coefficient which is calculated from daily data as reference values, you can calculate the error in determining the $\varphi$-coefficient calculated from monthly data. The average absolute error was $2.96 \%$. The largest errors $(4.37 \%$ and $3.88 \%)$ were obtained for the Sluch River at the Klepchany station and the Tsna River at the Dyatlovichi station, respectively. The results have shown that the use of average monthly runoff overestimates the value of the coefficient of natural runoff regulation. Taking into account the obtained relationship between the coefficients the $\varphi$-coefficient can be specified. Of course, using daily runoff data allows getting more accurate results, but this accuracy is unnecessary for multiple calculations. 

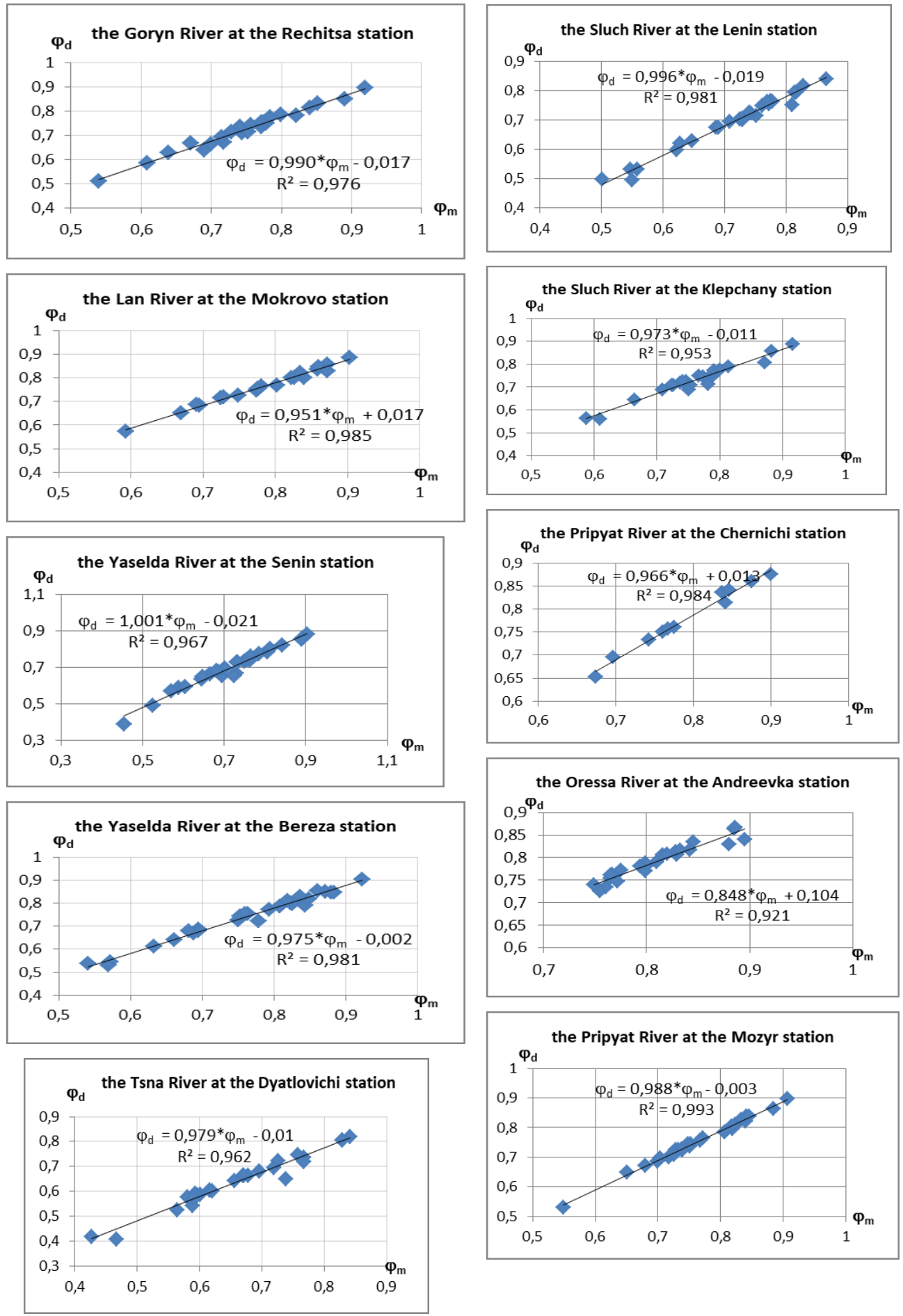

Fig. 3. The coefficient of natural runoff regulation for the daily $\left(\varphi_{d}\right)$ and monthly $\left(\varphi_{m}\right)$ data 
The time variability analysis of the coefficient of natural runoff regulation of the Pripyat River at the Mozyr station was carried out on the basis of combined graphs of normalized difference-integral curves and chronological graphs of changes in the $\varphi$-coefficient (Fig. 4). The the integral curves ordinates are calculated as an accumulated sum

$$
\sum\left(K_{i}-1\right) / c_{v}
$$

where $K_{i}=\varphi_{i} / \varphi_{0}$ is the modular coefficient of the coefficient of natural runoff regulation in the $\mathrm{i}$-th year $\left.\left(\varphi_{i}\right),\right), \varphi_{0}$ is its average value, $c_{v}$ is coefficient of variation, $i$ is a year.

The analysis of the difference-integral curves presented in Fig. 4 has shown that the series of $\varphi$-coefficient have two sets with critical period in 1970-1983. For all 10 gaugingstations an increase in the coefficient of natural runoff regulation by $15-56 \%$ after 1970 1983 was detected.

The coefficient of intra-annual runoff irregularity $d=1-\varphi$ is also used to analyze the runoff irregularity. This coefficient is equal to the control capacity required for intraannual runoff equalization. Since the spring flood is the main parameter of the water regime in the Pripyat River basin, it is advisable to include the parameters of the main high-water phase in the generalized indicators of intra-annual runoff irregularity. The most important indicator is the proportion of spring flooding $(d v p)$ in annual runoff. However, calculating the parameters of spring flooding has its own difficulties. It is especially difficult to distinguish the period of high water since the methods for determining the dates of the beginning and ending of the flood are mainly descriptive and do not have a clear algorithm for calculating. When snowmelt is very long in time or heavy rains fall on rivers then floodwaters are formed and their hydrographs have complex outlines and consist of several independent waves. In years with friendly snowmelt the slender single-peak floods are formed and characterized by a high intensity of rise and fall. The method of determining the main parameters of the spring flood including start and end dates of flood volume floods described in [28] and was used to determine the proportion of spring flooding.

In addition, it is also necessary to note the following feature: the calculation error can reach $30-40 \%$ when calculating the share of spring flood on the average monthly runoff if the average daily runoff is unavailable. The coefficient $d$ is completely determined by the $d v p$ value [29]. Thus, the results to periods for which the information about average daily runoff is not available can be extended by establishing a link between the $\mathrm{d}$ and $d v p$ indicators for the period with the available data. To do this a graph that reflects the relationship between the coefficient of natural runoff regulation and the share of spring flood runoff for the period with the available data on average daily runoff (1968-1997) for the Pripyat River at the Mozyr station was constructed (Fig. 5). 

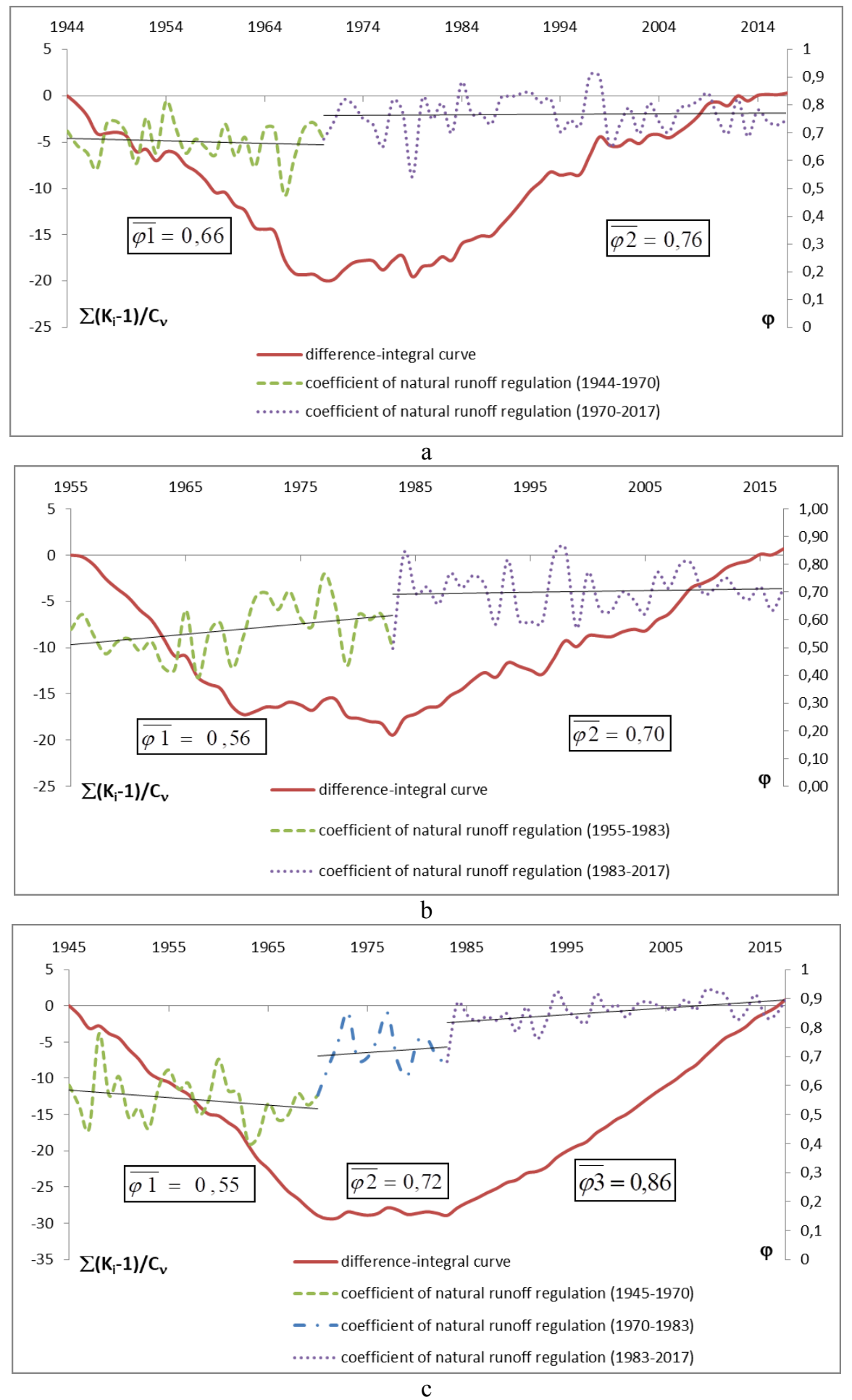

Fig. 4. Difference-integral curves and chronological graphs of the coefficient of natural runoff regulation ( $\mathrm{a}$ - the Pripyat River at the Mozyr station; $\mathrm{b}$ - the Tsna River at the Dyatlovichi station; $\mathrm{c}$ - the Yaselda River at the Bereza station) 


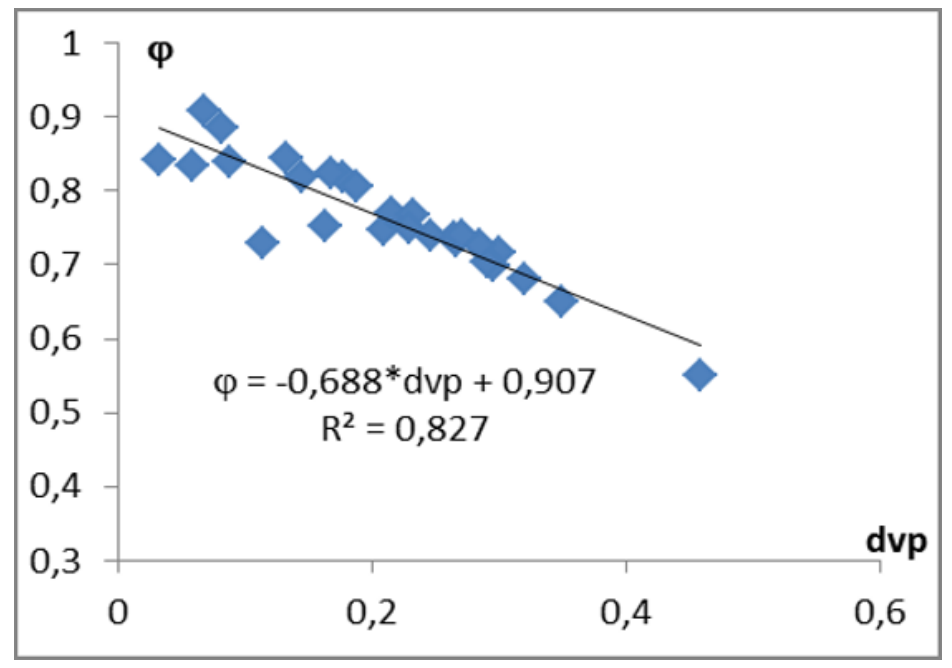

Fig. 5. Relationship between the share of spring flood runoff $d v p$ and the coefficient of natural runoff regulation $\varphi$

Fig. 5 shows that the share of spring flooding in annual runoff is closely related to its intra-annual unevenness $\left(\mathrm{R}^{2}=0.83\right)$. Moreover, as the share of spring flood runoff decreases this relationship weakens. Using the established relationship it is possible to obtain dvp indicators for the entire period under consideration (1944-2017). Fig. 6 shows changes in the $\varphi$-coefficients and $d v p$ for the Pripyat River at the Mozyr station.

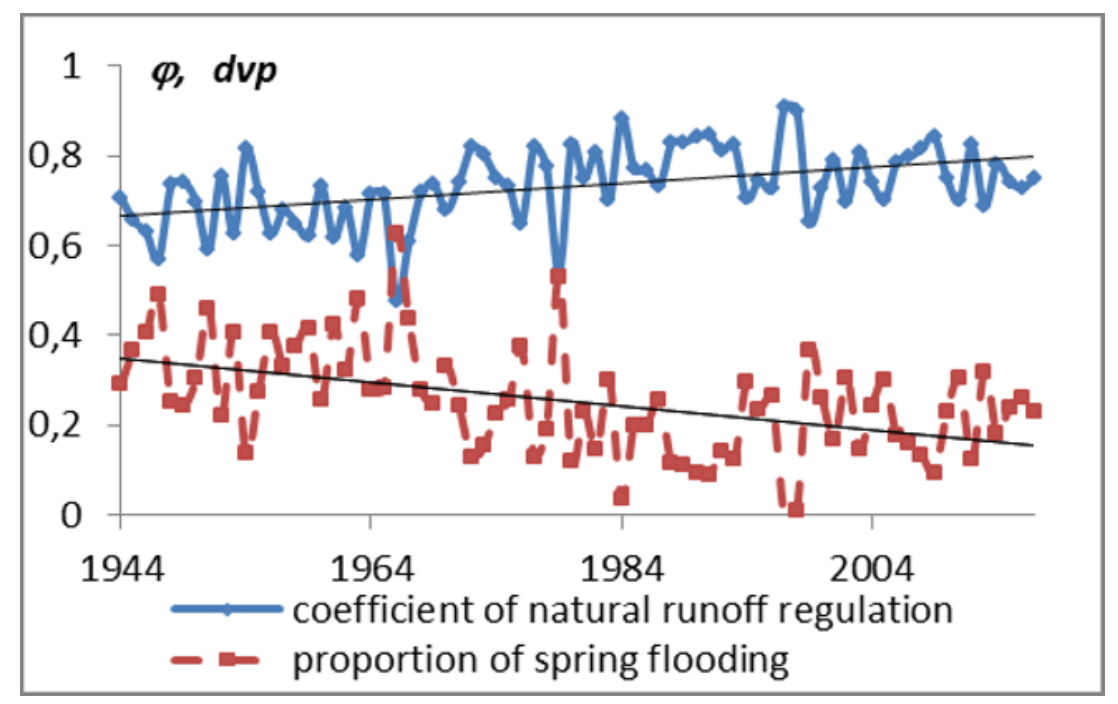

Fig. 6. Change in the share of spring flood runoff $d v p$ and the coefficient of natural runoff regulation $\varphi$ over a multi-year period

Changes in the natural runoff regulation are reflected in the form of hydrographs. There is a change in some phases of the water regime in the last decade when averaging hydrographs over decades (Fig. 7).

The changes in the average monthly runoff of the Pripyat River at the Mozyr station by decades for the period 1948-2017 in the form of a cross table were calculated for a more 
detailed study of changes in hydrographs. The cross-table values were the percentage of changes in runoff between the periods under consideration and the correlation coefficient between the periods.

Fig. 7 and calculated values show decrease in runoff in January in the last ten-year period (2008-2017) compared to the 4 previous ten-year periods. In March the changes in runoff in 2008-2017 were positive compared to all previous ten-year periods. However, it should be noted that these changes are gradually decreasing and in the current decade the changes in runoff in March compared to the previous decade will be negative, i.e. runoff in March will decrease. The same situation is observed in February. For this month, there has already been a decrease in runoff in the last decade by $5.53 \%$ compared to the period 1998-2007.

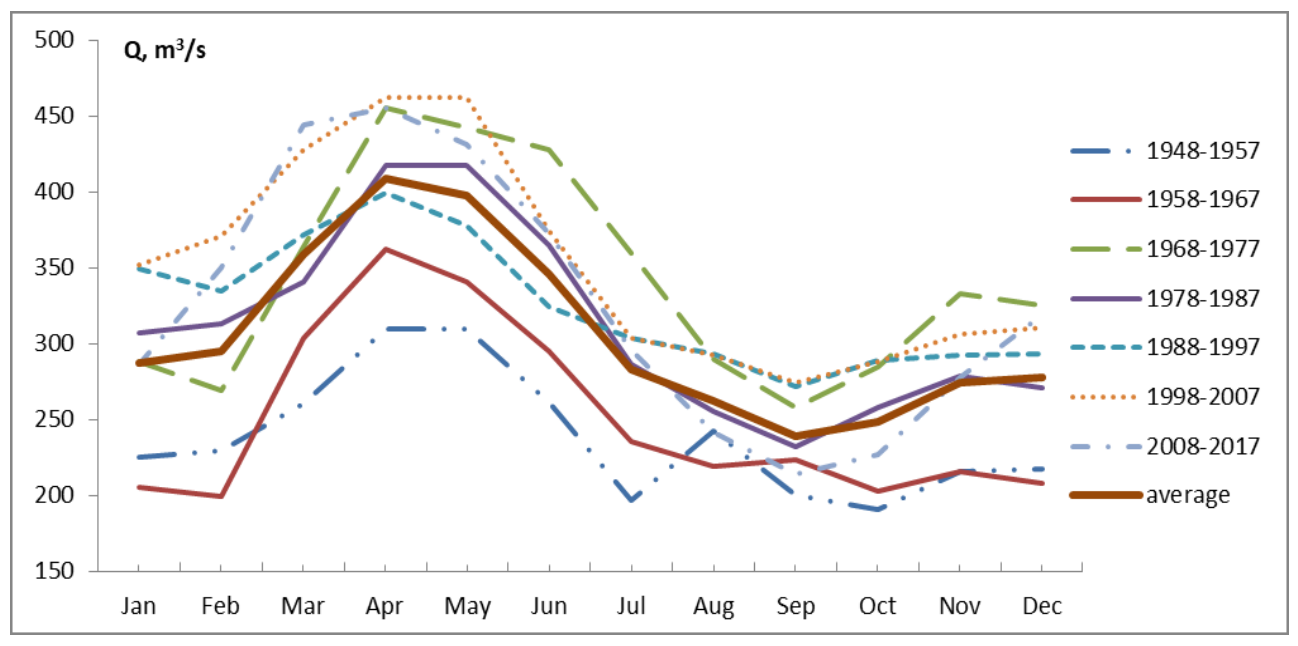

Fig. 7. Averaged by decades hydrographs of the Pripyat River at the Mozyr station

A significant decrease in runoff over the period 2008-2017 is observed in August, September, October, and November. The percentage of reduction reaches $21.88 \%$. When comparing the data on runoff changes for the period 2008-2017 with the average multi-year values for months for the period 1948-2017, there was positive trend in changes in most cases except August, September, and October. During these months runoff has decreased by an average value of $9 \%$ over the past decade.

Intra-annual unevenness of river runoff can act as a major factor of hydro-ecological safety of the territory. The number of years $(k)$ with exceeding the maximum water consumption by $15 \%$ was selected as a criterion for assessing the hydro-ecological safety of the territory. Table 1 shows the values of the $\varphi$-coefficient averaged over two periods and the calculated values of $\mathrm{k}$ for the Pripyat River at the Mozyr station.

Table 1. Averaged values of the $\varphi$-coefficient and the number of years with exceeding the maximum runoff of $15 \%$ security

\begin{tabular}{|c|c|c|}
\hline Period & $\begin{array}{c}\text { Averaged values } \\
\text { of the } \varphi \text {-coefficient }\end{array}$ & Calculated values of $k$ \\
\hline $1944-1980$ & 0.67 & 9 \\
\hline $1981-2017$ & 0.78 & 2 \\
\hline
\end{tabular}

Table 1 shows that during the period 1981-2017 the number of years with exceeding the maximum runoff of $15 \%$ security has significantly decreased and the $\varphi$-coefficient has increased by $16 \%$ compared to the previous period. 


\section{Conclusions}

The article considers the features of intra-annual runoff distribution of rivers in the Pripyat River basin. Changes in the nature of natural runoff regulation of rivers are shown based on data from 10 gauging-stations for the period 1945-2017. The relationship between the share of spring flooding and the coefficient of natural runoff regulation was established. There was an increase in the natural runoff regulation coefficient after $1970-1983$ by $15-56 \%$ and a decrease in the runoff irregularity for all rivers of the Pripyat River basin. The coefficient of natural runoff regulation of rivers can serve as an important factor of hydro-ecological safety of the territory. The number of years with the maximum runoff exceeding $15 \%$ safety decreases when the $\varphi$-coefficient increases for the rivers of the Pripyat River basin.

\section{References}

1. P. Choudhury, B. Sil, J of Hydrol., 385, 313 (2010)

2. R. Harding, G. Weedon, H. van Lanen, D. J of Hydrol., 518, 186 (2014)

3. S. Huang, F. Hattermann, V. Krysanova, A. Bronstert, Climate Change, 116, 631 (2013)

4. V. Mikhailov, Water Resources, 37, 145 (2010)

5. Y. Sang, D. Wang, J. Wu, Q. Zhu, L. Water Sci. and Eng., 4, 36 (2011)

6. A. Volchak, S. Parfomuk, Limnol. Rev., 4, 185 (2018)

7. N. Bosch, J. Allan, D. Dolan, H. Han, R. Richards, J of Great Lakes Res., 37, 268 (2011)

8. J. Makarewicz, T. Lewis, E. Rea, M. Winslow, D. Pettenski, J of Great Lakes Res., 41, 123 (2014)

9. E. Schiefer, E. Petticrew, R. Immell, M. Hassab, D. Sonderegger, Anthropocene, 3, 61 (2013)

10. V. Krysanova, D. Müller-Wohlfeil, A. Becker, Ecol. Model., 106, 261 (1998)

11. A. Lobanova, H. Koch, S. Liersch, F. Hattermann, Hydrol. Proc., 30, 5039 (2016)

12. J. Stagl, F. Hattermann, Water, 7, 6139 (2015)

13. M. Wortmann, V. Krysanova, Z. Kundzewicz, B. Su, X. Li, Hydrol. Proc., 28, 6337 (2014)

14. S. Shaghaghi, H. Bonakdari, A. Gholami, I. Ebtehaj, M. Zeinolabedini, Appl. Math. and Computation, 313, 271 (2017)

15. W. Wang, K. Chau, C. Cheng, L. Qiu, J Hydrology, 374, 294 (2009)

16. A. Zaji, H. Bonakdari, B. Gharabaghi, Acta Geophysica, 66, 717 (2018)

17. M. Zeynoddin, H. Bonakdari, A. Azari, I. Ebtehaj, B. Gharabaghi, H. Madavar, J Env. Man., 222, 190 (2018)

18. A. Volchak, I. Kirvel, S. Parfomuk, R. Makhambetova, Limnol. Rev., 4, 221 (2013)

19. I. Kirvel, A. Volchak, S. Parfomuk, Quaest. Geogr., 35, 57 (2016)

20. A. Furat, M. Al-Faraj, M. Scholz, Wat. Res. Man., 28, 5477 (2014)

21. D. Hannah, B. Smith, A. Gurnell, G. McGregor, Hydrol. Proc., 14, 317 (2000)

22. L. Liucci, D. Valigi, S. Casadei, Wat. Res. Man., 28, 881 (2014)

23. X. Tu, V. Singh, X. Chen, L. Chen, Q. Zhang, Y. Zhao, Wat. Res. Man., 29, 2677 (2015) 
24. A. Volchak, O. Natarova, Scientific notes of RSMU, 52, 67 (2018)

25. An. Volchek, Scientific and technical problems of water management and energy complex in modern conditions of Belarus, 109 (2011)

26. V. Evstigneev, D. Magritsky, River flow and hydrological calculations (Moscow, 2013)

27. A. Komlev, G. Proskurina, Meteorology and Hydrology, 10, 95 (1977)

28. A. Volchak, S. Parfomuk, S. Sidak, Natural environment of Polesie: features and prospects of development, 11, 29 (2018)

29. N. Frolova, D. Nesterenko, N. Schoenberg, Bul. Mosc. Un. Geography, 6, 8 (2010) 